\title{
Seleção de genótipos de arroz para integrar uma mistura varietal visando o controle da brusone
}

\author{
Gil Rodrigues dos Santos ${ }^{1}$, Jaíza Francisca Ribeiro Chagas ${ }^{1}$, Manoel Delintro de Castro Neto $^{2}$, Rodrigo Fidelis ${ }^{1}$, \\ Evelynne Urzedo Leão ${ }^{1}$
}

${ }^{1}$ UFT - Universidade Federal do Tocantins, CX. Postal 66. CEP: 77402-970, Gurupi-TO. ${ }^{2}$ IFTO - Instituto Federal de Educação, Ciência e Tecnologia do Tocantins, CEP: 77493000, Lagoa da Confusão, TO.

Autor para correspondência: Gil Rodrigues dos Santos (gilrsan@uft.edu.br)

Data de chegada: 19/02/2016. Aceito para publicação em: 20/06/2017.

$10.1590 / 0100-5405 / 2161$

\section{RESUMO}

Santos, G.R.; Chagas, J.F.R.; Castro Neto, M.D.; Fidelis, R.; Leão, E.U. Seleção de genótipos de arroz para integrar uma mistura varietal visando o controle da brusone. Summa Phytopathologica, v.43, n.4, p.290-296, 2017.

A brusone, causada por Magnaporthe oryzae (Herbert) Barr é uma das doenças mais importantes na cultura do arroz. Várias estratégias de manejo da doença, como o uso de genótipos resistentes têm sido utilizadas, entretanto, o grande número de raças do patógeno dificulta a obtenção de cultivares com resistência durável. Neste contexto, o uso da mistura varietal pode constituir uma estratégia viável e promissora no controle da doença. Assim, objetivou-se com este estudo avaliar a reação de cultivares de arroz às raças de $M$. oryzae e a eficiência da mistura varietal na redução da severidade da brusone em condições de várzea e terras altas no estado do Tocantins. Para avaliar a eficiência da mistura varietal, foram semeados 37 genótipos em linhas isoladas e em mistura. Avaliou-se a severidade da brusone nas folhas, ao longo do ciclo da cultura, a incidência da doença nas panículas e a produtividade. Houve variação na reação dos genótipos estudados frente às principais raças inoculadas. A composição de arroz foi eficaz na redução da severidade da brusone das folhas e das panículas e apresentou um aumento na produtividade, tanto em condições de várzeas como em terra altas.

Palavras-chave:Oryza sativa, Magnaporthe oryzae, variedades compostas, resistência.

\section{ABSTRACT}

Santos, G.R.; Chagas, J.F.R.; Castro Neto, M.D.; Fidelis, R.; Leão, E.U. Selection of rice genotypes to integrate a varietal mixture for blast control. Summa Phytopathologica, v.43, n.4, p.290-296, 2017.

Blast, caused by Magnaporthe oryzae (Herbert) Barr, is one of the most important diseases affecting the rice crop. Several strategies for the disease management, such as use of resistant genotypes, have been adopted; however, the large number of pathogen races makes difficult to obtain cultivars of durable resistance. In this context, using a varietal mixture may be a viable and promising strategy for the disease control. Thus, the aim of this study was to evaluate the reaction of rice cultivars to M. oryzae races and the efficiency of the varietal mixture in reducing the severity of blast under lowland and upland conditions in Tocantins State. To evaluate the efficiency of the varietal mixture, 37 genotypes were sown in isolated lines and in mixture. The severity of leaf blast was evaluated over the crop cycle, as well as the incidence of panicle blast and the crop yield. There was variation in the reaction of the studied genotypes to the major inoculated races. The rice composition was effective in reducing blast severity on leaves and panicles and showed an increase in productivity under both lowland and upland conditions.

Keywords: Oryza sativa, Magnaporthe oryzae, composed varieties, resistance.

A brusone causada por Magnaporthe oryzae (Herbert) Barr (3) anamorfo Pyricularia grisea (Cooke) Sacc é a principal doença do arroz (Oryza sativa L.) e tem sido um obstáculo para a produção no mundo (7). A doença pode ocorrer em todos os órgãos e fases de desenvolvimento da cultura (19), resultando em redução da produtividade (12). Estes danos são decorrentes principalmente da redução do peso dos grãos e, em alguns casos, da esterilização completa das panículas.

A utilização de genótipos com resistência genética à doença constitui-se como principal medida para o manejo da brusone na cultura do arroz. Entretanto, seu uso tem sido dificultado devido à elevada variabilidade genética do patógeno, o que resulta na rápida adaptação das raças aos cultivares disponíveis no mercado (12). Segundo Santos et al. (17), devido a esta alta variabilidade e as condições ambientais favoráveis à doença, os genótipos com resistência vertical deixam de ser efetivos em menos de três anos nas condições do estado do Tocantins, região Norte do Brasil. O uso de fungicidas, nestas condições, apresenta baixa eficiência na redução da severidade da doença em condição de campo (16), embora seja a medida de controle muito utilizada.

Novas estratégias estão sendo estudadas constantemente para o controle da brusone no arroz. Neste contexto, o uso da mistura varietal ou variedades compostas é uma estratégia promissora para controlar de forma sustentável populações do patógeno, pois fornece uma maior supressão da doença, podendo levar a uma resistência estável à brusone (20). Esta técnica consiste no plantio de uma mistura de sementes, de duas ou mais cultivares, com características agronômicas compatíveis. É fundamental que os cultivares componentes da mistura apresentem uma maior similaridade quanto a algumas características agronômicas como, altura de plantas, altura de panícula, época de florescimento, ciclo e arquitetura de plantas (6). Na China, Zhu et al. (20), testaram uma variedade suscetível e outra resistente à brusone, ambas cultivadas em monocultura e em mistura. Os autores observaram uma redução de $94 \%$ na severidade da brusone nas misturas quando comparados aos 
plantios separados de cada genótipo. Embora proporcionem resultados satisfatórios, poucos estudos são relatados no controle da brusone do arroz utilizando a mistura varietal, no Brasil e em outras regiões orizícolas do mundo.

Considerando a importância econômica da cultura do arroz no Brasil e no mundo, a elevada severidade da brusone aliados às dificuldades de controle, objetivou-se com este estudo avaliar a reação de genótipos de arroz às raças de $M$. oryzae e a eficiência da mistura varietal de arroz na redução da severidade da brusone em condições de várzea e terras altas no estado do Tocantins.

\section{MATERIAL E MÉTODOS}

Reação de cultivares de arroz às raças de Magnaporthe oryzae

Foram semeados 37 genótipos de arroz em bandejas plásticas (45 x 30 x $10 \mathrm{~cm}$ ) contendo 3,5 litros de substrato comercial. Em cada bandeja foram semeados oito genótipos em oito linhas, nas quais foram plantadas 12 sementes por linha em três repetições. Após a semeadura, as bandejas foram mantidas em na casa-de-vegetação, sob temperatura constante de $26^{\circ} \mathrm{C}$. Não foi realizada adubação de plantio em função do tempo de permanência da cultura no substrato e dos teores de nutrientes presentes no mesmo (Ca, $\mathrm{Mg}, \mathrm{Al}, \mathrm{H}+\mathrm{Al}, 16.4,10.1,0.24,10.1 \mathrm{cmol}$. $\mathrm{dm}^{-3}$, respectivamente; $\mathrm{K}, 709.5 \mathrm{ppm}, \mathrm{P}, 362 \mathrm{ppm}, 10.7 \%$ de matéria orgânica e pH $5.2 \mathrm{em} \mathrm{CaCl}_{2}$ ). A adubação de cobertura foi realizada aos 15 dias após a emergência utilizando-se $4 \mathrm{~g}$ de uréia dissolvida em $100 \mathrm{~mL}$ de água por bandeja, com a finalidade de predispor as plantas ao ataque do fungo $M$. oryzae.

Semearam-se os seguintes genótipos de arroz irrigado: Mutante; BRS Formoso; BRS Diamante; CNA 8502; Javaé; BRS Metica; BRS Alvorada; BRS guará; BRS Jaçanã, BRS Fronteira; Ouro Minas; BRS Jaburu; BRS Biguá; BRS Taim; BRS Pelotas; CNAI 9930; Epagri; Irga 409; Irga 417; Cica 8; Bg 90-2; Ir 36; Irri 344; Oryzica 1; Oryzica Lhanos 4; Oryzica Lhanos 5; BRS Colômbia; Basmati; Eloni; Ir 34; Tetep; Cica 7; Cica 9; Epagri 114; Best; CNAI 9022 e CNA 5287.

Os isolados monospóricos utilizados neste estudo foram multiplicados a partir de placas matrizes pertencentes ao Laboratório de Fitopatologia da Universidade Federal do Tocantins, os quais foram previamente obtidos de lavouras comerciais e de parcelas experimentais de arroz, instaladas no estado do Tocantins por Dias Neto et al. (7). Das raças encontradas por este autor, foram utilizadas as 10 mais prevalecentes no estudo, sendo: IA-1, IC-1, ID-1, IA-65, ID-9, IB-1, IA-33, IA-41, IB-33 e IB-4.

A metodologia utilizada para identificação das raças foi a proposta por Atkins et al. (1), onde a partir de plantas infectadas, foram obtidos os isolados monospóricos e a identificação das raças fisiológicas de $M$. oryzae foi realizada por meio da observação visual após a inoculação dos isolados monospóricos na Série Internacional de Diferenciadoras. As oito diferenciadoras internacionais utilizadas para diferenciação de raças fisiológicas foram as cultivares Raminad Str-3, Zenith, NP-125, Usen, Dular, Kanto 51, Sha-tiao-tsao e Caloro. A fase de identificação das raças foi composta basicamente pelas seguintes etapas: plantio das diferenciadoras, multiplicação do inóculo, inoculação do patógeno nas diferenciadoras e avaliação das reações, sendo esta seguida da verificação dos dados na chave de identificação.

As raças do fungo foram inoculadas separadamente em cada bandeja contendo os genótipos. As inoculações foram realizadas aos 25 DAE (dias após a emergência), com uma suspensão conidial quantificada em Câmara de Neubauer e ajustada para a concentração de
$3 \times 1,6 \times 10^{5}$ conidios/mL, pulverizando-se, com um borrifador manual, $20 \mathrm{~mL}$ da suspensão de inóculo em cada bandeja. Após as inoculações, as plantas foram mantidas durante 24 horas, em câmara úmida escura, com temperatura média de $25^{\circ} \mathrm{C}$ e umidade relativa acima de $95 \%$, proporcionada por um umidificador elétrico. Após esse período, as plantas foram mantidas em casa-de-vegetação, com temperatura em torno de $25^{\circ} \mathrm{C}$.

A avaliação da doença nas folhas foi realizada aos nove dias após a inoculação, através de análise visual, utilizando-se uma escala de notas variando de 0 a 9 , proposta por Leung et al. (9), onde: 0 - ausência total de lesões; 1 - pequenas lesões de cor marrom e que não se desenvolvem; 3 - lesões pequenas, na sua maioria pouco alongada com pouco ou nenhuma esporulação; 4 - poucas lesões típicas e esporulativas, com centro cinza caracterizada por algumas lesões abertas; 5 - muitas lesões típicas e altamente esporulativas que podem estar isoladas ou coalescentes; 7- lesões coalescentes e com mais de 50\% da área foliar afetada; 9 - muitas lesões que coalescem, causando murcha e morte das folhas. As plantas foram classificadas como resistente quando receberam notas de severidade menor ou igual a 3, e suscetíveis quando a nota de severidade foi igual ou superior a 4 .

\section{Mistura varietal no controle da brusone do arroz}

Os ensaios foram conduzidos na área experimental da Embrapa Arroz e Feijão, localizada no Projeto Rio Formoso, município de Formoso do Araguaia-TO, em condições de várzea úmida, e no município de Gurupi-TO em condições de terras altas. Foi utilizado delineamento experimental de blocos ao acaso com 38 tratamentos e três repetições. Os tratamentos foram constituídos dos 37 genótipos de arroz, utilizados no item anterior, e a mistura varietal composta pela mistura de sementes dos 37 genótipos.

Os genótipos utilizados na mistura foram previamente selecionados através de um ensaio de caracterização agronômica e fenológica, onde características como altura de planta, ciclo da cultura e características dos grãos foram analisadas, pois cumprem um dos requisitos básicos para se compor um mistura varietal (dados não mostrados). A proporção de sementes de cada genótipo foi de $100 \mathrm{~g}$, onde após a mistura de todas as sementes em um balde de $10 \mathrm{~kg}$, retirou-se uma amostra de $100 \mathrm{~g}$ para o plantio.

Cada parcela foi constituída de duas linhas de cinco metros, totalizando 76 linhas (2 linhas de 37 genótipos e 2 linhas da mistura) em cada bloco. A densidade de semeadura utilizada foi de 100 sementes por metro. O controle de plantas daninhas foi feito manualmente entre as linhas e com capinas mecânicas entre as parcelas, nos dois locais. Em ambos os experimentos, foi utilizado o espaçamento de $20 \mathrm{~cm}$ entre linhas. Na adubação de plantio, foram utilizados $350 \mathrm{~kg} \cdot \mathrm{ha}^{-1} \mathrm{de}$ NPK (05-30-15) e em cobertura, foram utilizados $100 \mathrm{~kg}$ ha ${ }^{-1}$ de uréia. No ensaio conduzido em várzea úmida, a irrigação foi realizada por inundação aos 30 dias após a germinação. No ensaio de terras altas, além das precipitações pluviais, a irrigação foi complementada por aspersão durante todo o ciclo da cultura, utilizando-se uma lâmina d'água de 19 mm.dia ${ }^{-1}$, nos períodos sem precipitação.

Nos dois experimentos a doença ocorreu a partir do inóculo natural presente nas áreas. Ao surgimento dos primeiros sintomas da brusone foram iniciadas as avaliações da severidade da doença em cada parcela. Para a avaliação da severidade nas folhas, foi adotada a mesma escala de notas de 0 a 9 proposta por Leung et al. (9), descrita no item anterior. A identificação do patógeno e as raças foram realizadas através da coleta e análise de folhas e panículas sintomáticas.

$\mathrm{Na}$ condição de várzea, as avaliações da severidade da brusone 
foram realizadas aos 33, 38, 45, 52 e 59 dias após o plantio (DAP). Em terras altas, as avaliações foram realizadas aos 37, 44, 51, 58 e 65 DAP. Os valores das notas de severidade foram transformados em porcentagem de área foliar lesionada e utilizados para montar o gráfico da curva de progresso da brusone. Para determinar a incidência da brusone nas panículas, foram coletadas 50 panículas, em cada parcela, com grãos na fase pastosa. A incidência, por parcela, foi considerada pela relação entre o número de afilhos doentes no total de afilhos avaliados.

Para determinação da produtividade, foi realizada a colheita e a pesagem dos grãos das duas linhas centrais de cada parcela, ao final do ciclo de cada genótipo. Os dados de produtividade foram expressos em kg.ha ${ }^{-1}$. Os dados de incidência de brusone nas panículas e de produtividade foram submetidos à análise de variância e as médias, quando necessário, foram comparadas entre si através do teste de Scott-Knot $(\mathrm{p} \leq 0,05)$.

\section{RESULTADOS E DISCUSSÃO}

\section{Reação de cultivares de arroz a raças de $M$. oryzae}

Foram observadas reações distintas nos genótipos de arroz às diferentes raças de $M$. oryzae inoculadas. Nenhuma das raças utilizadas foi capaz de infectar todos os genótipos avaliados (Tabela 1). Observouse que 31 genótipos de arroz apresentaram resistência às raças IB-1 e IB-33, enquanto que as raças mais virulentas foram: ID-1; IA-1; IA-41; IA-33; ID-9 e IC-1, as quais infectaram em média 10 dos 37 genótipos avaliados.

De acordo com os resultados obtidos no presente trabalho e com os dados relatados na literatura, existe uma elevada variabilidade entre os genótipos de arroz quanto à reação à brusone foliar, a qual depende da estrutura populacional do patógeno predominante na região. Rodríguez et al. (15) mostraram alta variabilidade nos genótipos de arroz para a brusone da folha e permitiram concluir que o grau de resistência de alguns destes genótipos é baixo e necessitam de medidas complementares de controle. Prabhu \& Filippi (13) demonstram a importância da incorporação de genes de resistência nos novos genótipos contra as raças mais frequentes do patógeno.

A caracterização da variabilidade de $M$. oryzae nos locais onde se realizam os plantios comerciais de arroz, como no estado do Tocantins, por exemplo, é essencial para entender a dinâmica da virulência do patógeno e adotar estratégias adequadas para aumentar a durabilidade da resistência das cultivares. A elevada variabilidade nas populações do patógeno dificulta o manejo da brusone através da utilização da resistência genética em condições de plantios comerciais com histórico da presença do patógeno, onde o controle químico tem se tornado indispensável para a obtenção de uma boa produtividade. A maioria dos genótipos utilizados neste ensaio apresentam um elevado potencial para compor uma mistura varietal. No entanto, ressalta-se que estes genótipos podem ser atacados por outras raças que não foram detectadas no presente estudo.

\section{Mistura varietal no controle da brusone do arroz}

Em condição de várzea, a mistura varietal suprimiu a alta severidade da brusone observada nas folhas dos genótipos Best, Cica 7, Tetep, Epagri 114, Epagri 109, BRS Taim, Cica 8 e BRS Ouro Minas, plantados isoladamente (Figura 1A; Tabela 2). Os genótipos: BRS Formoso, BRS Diamante, CNA 8502, BRS Javaé, Metica 1, BRS Alvorada, BRS Guará, BRS Jaçanã, BRS Fronteira, BRS Jaburu, BRS Biguá, Pelotas,
Tabela 1. Reação de genótipos de arroz à diferentes raças de Magnaporthe oryzae.

\begin{tabular}{|c|c|c|c|c|c|c|c|c|c|c|}
\hline \multirow{2}{*}{ Genótipos } & \multirow{2}{*}{\multicolumn{10}{|c|}{ Isolados de Magnaporthe oryzae }} \\
\hline & & & & & & & & & & \\
\hline Mutante & $\mathrm{S}^{1}$ & $\mathrm{R}$ & S & S & $\mathrm{S}$ & $\mathrm{R}$ & $\mathrm{S}$ & $\mathrm{S}$ & $\mathrm{R}$ & $\mathrm{R}$ \\
\hline BRS Formoso & $\mathrm{R}$ & $\mathrm{R}$ & $\mathrm{S}$ & $\mathrm{R}$ & $\mathrm{S}$ & $\mathrm{S}$ & $\mathrm{R}$ & $\mathrm{R}$ & $\mathrm{S}$ & $\mathrm{R}$ \\
\hline Diamante & $\mathrm{R}$ & $\mathrm{R}$ & $\mathrm{R}$ & $\mathrm{S}$ & $\mathrm{S}$ & $\mathrm{R}$ & $\mathrm{R}$ & $\mathrm{S}$ & $\mathrm{R}$ & $\mathrm{R}$ \\
\hline CNA 8502 & $\mathrm{R}$ & S & $\mathrm{R}$ & $\mathrm{R}$ & $\mathrm{R}$ & $\mathrm{R}$ & S & $\mathrm{S}$ & $\mathrm{R}$ & $\mathrm{R}$ \\
\hline Javaé & $\mathrm{R}$ & $\mathrm{R}$ & $\mathrm{R}$ & $\mathrm{R}$ & $\mathrm{R}$ & $\mathrm{R}$ & $\mathrm{R}$ & $\mathrm{R}$ & $\mathrm{R}$ & $\mathrm{R}$ \\
\hline Metica 1 & $\mathrm{~S}$ & $\mathrm{R}$ & S & S & S & $\mathrm{R}$ & $\mathrm{R}$ & $\mathrm{R}$ & S & $\mathrm{R}$ \\
\hline BRS Alvorada & $\mathrm{R}$ & $\mathrm{R}$ & $\mathrm{R}$ & $\mathrm{R}$ & S & $\mathrm{S}$ & $\mathrm{R}$ & $\mathrm{R}$ & $\mathrm{R}$ & $\mathrm{R}$ \\
\hline BRS Guará & $\mathrm{R}$ & $\mathrm{R}$ & $\mathrm{R}$ & $\mathrm{R}$ & $\mathrm{R}$ & $\mathrm{R}$ & $\mathrm{R}$ & $\mathrm{R}$ & S & $\mathrm{R}$ \\
\hline BRS Jaçanã & $\mathrm{R}$ & $\mathrm{R}$ & $\mathrm{R}$ & $\mathrm{R}$ & $\mathrm{R}$ & $\mathrm{R}$ & $\mathrm{R}$ & $\mathrm{R}$ & $\mathrm{R}$ & $\mathrm{R}$ \\
\hline BRS Fronteira & $\mathrm{R}$ & $\mathrm{R}$ & $\mathrm{R}$ & $\mathrm{R}$ & $\mathrm{R}$ & $\mathrm{R}$ & $\mathrm{R}$ & $\mathrm{R}$ & $\mathrm{S}$ & $\mathrm{R}$ \\
\hline BRS Ouro Minas & S & $\mathrm{R}$ & S & $\mathrm{R}$ & $\mathrm{R}$ & $\mathrm{R}$ & $\mathrm{R}$ & $\mathrm{S}$ & $\mathrm{R}$ & $\mathrm{R}$ \\
\hline BRS Jaburu & $\mathrm{R}$ & $\mathrm{R}$ & $\mathrm{R}$ & $\mathrm{R}$ & $\mathrm{R}$ & $\mathrm{R}$ & $\mathrm{R}$ & $\mathrm{R}$ & $\mathrm{R}$ & $\mathrm{R}$ \\
\hline BRS Biguá & $\mathrm{R}$ & $\mathrm{R}$ & $\mathrm{R}$ & $\mathrm{R}$ & $\mathrm{R}$ & $\mathrm{R}$ & $\mathrm{R}$ & $\mathrm{R}$ & $\mathrm{R}$ & $\mathrm{R}$ \\
\hline BRS Taim & $\mathrm{R}$ & S & $\mathrm{R}$ & $\mathrm{R}$ & $\mathrm{R}$ & $\mathrm{S}$ & S & $\mathrm{R}$ & $\mathrm{R}$ & $\mathrm{R}$ \\
\hline BRS Pelotas & $\mathrm{R}$ & $\mathrm{R}$ & $\mathrm{R}$ & $\mathrm{R}$ & $\mathrm{S}$ & $\mathrm{S}$ & $\mathrm{S}$ & $\mathrm{S}$ & $\mathrm{S}$ & $\mathrm{S}$ \\
\hline CNAi 9930 & $\mathrm{R}$ & $\mathrm{R}$ & $\mathrm{R}$ & $\mathrm{R}$ & S & $\mathrm{R}$ & $\mathrm{R}$ & $\mathrm{R}$ & $\mathrm{R}$ & S \\
\hline Epagri 109 & $\mathrm{~S}$ & $\mathrm{~S}$ & $\mathrm{~S}$ & $\mathrm{R}$ & $\mathrm{R}$ & $\mathrm{R}$ & $\mathrm{R}$ & $\mathrm{S}$ & $\mathrm{S}$ & $\mathrm{R}$ \\
\hline BR Irga 409 & $\mathrm{R}$ & $\mathrm{R}$ & $\mathrm{R}$ & $\mathrm{S}$ & $\mathrm{S}$ & $\mathrm{S}$ & $\mathrm{S}$ & $\mathrm{S}$ & $\mathrm{S}$ & $\mathrm{S}$ \\
\hline Irga 417 & $\mathrm{R}$ & $\mathrm{R}$ & $\mathrm{R}$ & S & S & $\mathrm{R}$ & $\mathrm{R}$ & $\mathrm{R}$ & $\mathrm{R}$ & $\mathrm{S}$ \\
\hline Cica 8 & $\mathrm{R}$ & $\mathrm{S}$ & $\mathrm{R}$ & $\mathrm{R}$ & $\mathrm{R}$ & $\mathrm{S}$ & $\mathrm{R}$ & $\mathrm{R}$ & $\mathrm{R}$ & $\mathrm{R}$ \\
\hline BG 90-2 & $\mathrm{R}$ & $\mathrm{R}$ & $\mathrm{R}$ & $\mathrm{R}$ & $\mathrm{R}$ & $\mathrm{R}$ & $\mathrm{R}$ & $\mathrm{R}$ & $\mathrm{R}$ & $\mathrm{R}$ \\
\hline IR 36 & S & $\mathrm{R}$ & S & $\mathrm{R}$ & $\mathrm{R}$ & $\mathrm{R}$ & $\mathrm{R}$ & $\mathrm{S}$ & $\mathrm{R}$ & $\mathrm{R}$ \\
\hline Irri 344 & $\mathrm{R}$ & $\mathrm{R}$ & $\mathrm{R}$ & $\mathrm{R}$ & $\mathrm{R}$ & $\mathrm{R}$ & $\mathrm{R}$ & $\mathrm{R}$ & $\mathrm{R}$ & $\mathrm{R}$ \\
\hline Orizica 1 & $\mathrm{R}$ & $\mathrm{R}$ & $\mathrm{R}$ & $\mathrm{R}$ & $\mathrm{R}$ & $\mathrm{R}$ & $\mathrm{R}$ & $\mathrm{R}$ & $\mathrm{R}$ & $\mathrm{R}$ \\
\hline Orizica Lhanos 4 & $\mathrm{R}$ & $\mathrm{R}$ & $\mathrm{R}$ & $\mathrm{R}$ & $\mathrm{R}$ & $\mathrm{R}$ & $\mathrm{R}$ & $\mathrm{R}$ & $\mathrm{R}$ & $\mathrm{R}$ \\
\hline Orizica Lhanos 5 & $\mathrm{R}$ & $\mathrm{R}$ & $\mathrm{R}$ & S & $\mathrm{R}$ & $\mathrm{R}$ & $\mathrm{R}$ & $\mathrm{R}$ & $\mathrm{S}$ & $\mathrm{R}$ \\
\hline Colômbia & S & $\mathrm{R}$ & S & S & S & $\mathrm{S}$ & S & $\mathrm{S}$ & $\mathrm{R}$ & $\mathrm{R}$ \\
\hline Basmati & $\mathrm{R}$ & $\mathrm{R}$ & $\mathrm{R}$ & S & $\mathrm{R}$ & S & $\mathrm{R}$ & $\mathrm{R}$ & $\mathrm{R}$ & $\mathrm{R}$ \\
\hline Eloni & $\mathrm{R}$ & $\mathrm{R}$ & $\mathrm{R}$ & S & $\mathrm{R}$ & $\mathrm{R}$ & $\mathrm{R}$ & $\mathrm{R}$ & $\mathrm{R}$ & $\mathrm{R}$ \\
\hline IR 34 & $\mathrm{R}$ & $\mathrm{S}$ & $\mathrm{R}$ & $\mathrm{R}$ & $\mathrm{R}$ & $\mathrm{R}$ & $\mathrm{R}$ & $\mathrm{R}$ & $\mathrm{R}$ & $\mathrm{R}$ \\
\hline Tetep & $\mathrm{R}$ & $\mathrm{R}$ & $\mathrm{R}$ & $\mathrm{R}$ & $\mathrm{R}$ & $\mathrm{R}$ & S & $\mathrm{R}$ & $\mathrm{R}$ & $\mathrm{R}$ \\
\hline Cica 7 & $\mathrm{~S}$ & $\mathrm{R}$ & $\mathrm{S}$ & $\mathrm{R}$ & $\mathrm{R}$ & $\mathrm{S}$ & $\mathrm{S}$ & $\mathrm{S}$ & $\mathrm{S}$ & $\mathrm{S}$ \\
\hline Epagri 114 & S & $\mathrm{R}$ & $\mathrm{S}$ & S & $\mathrm{R}$ & $\mathrm{R}$ & $\mathrm{R}$ & $\mathrm{R}$ & $\mathrm{R}$ & $\mathrm{R}$ \\
\hline Cica 9 & $\mathrm{R}$ & $\mathrm{R}$ & $\mathrm{R}$ & S & $\mathrm{R}$ & $\mathrm{R}$ & $\mathrm{R}$ & $\mathrm{R}$ & $\mathrm{R}$ & $\mathrm{R}$ \\
\hline Best & $\mathrm{R}$ & $\mathrm{S}$ & $\mathrm{R}$ & $\mathrm{R}$ & $\mathrm{R}$ & $\mathrm{R}$ & $\mathrm{S}$ & $\mathrm{S}$ & $\mathrm{R}$ & $\mathrm{R}$ \\
\hline CNAI9022 & $\mathrm{S}$ & $\mathrm{R}$ & $\mathrm{R}$ & $\mathrm{R}$ & $\mathrm{S}$ & $\mathrm{S}$ & $\mathrm{R}$ & $\mathrm{R}$ & $\mathrm{R}$ & $\mathrm{R}$ \\
\hline CNAI 5287 & $\mathrm{R}$ & $\mathrm{R}$ & $\mathrm{S}$ & $\mathrm{S}$ & $\mathrm{S}$ & $\mathrm{R}$ & $\mathrm{R}$ & $\mathrm{R}$ & $\mathrm{S}$ & $\mathrm{S}$ \\
\hline
\end{tabular}

${ }^{1} \mathrm{R}($ Resistente $)=$ nota de severidade de 0 a 3; $\mathrm{S}($ Sucetível $)=$ nota de severidade de 4-9.

CNAI 9930, Irga 409, Irga 417, Bg 90-2, Ir 36, Irri 344, Oryzica 1, Oryzica Lhanos 4, Orizica Lhanos 5, BRS Colômbia, Basmati, Eloni, Ir 34, Cica 9, CNAI 9022 e CNA 5287 plantados em linhas isoladas apresentaram baixa severidade da doença em todo o ciclo da cultura. Este fato pode ter ocorrido, provavelmente, devido à inexistência ou baixa frequência de raças específicas, capazes de infectar estes 
genótipos. Os genótipos Best, Cica 7, Tetep, Epagri 114, Epagri 109, BRS Taim, Cica 8 e BRS Ouro Minas, entretanto, apresentaram maior suscetibilidade nas condições de várzea.

Nakajima et al. (10), em ensaio conduzido na Ilha de Madagascar, observaram a eficiência da multilinha composta por dez linhas isogênicas do genótipo de arroz Sasanishiki, na supressão da brusone do arroz. Segundo os autores, a severidade da brusone e o percentual de plantas doentes na mistura das linhas foram menores que o observado nos plantios isolados de cada uma delas. Sester et al. (18), também em Madagascar avaliando uma mistura de dois genótipos de arroz, Fofifa 154 altamente suscetível e Fofifa 172 resistente, observaram que a incidência e a severidade da brusone foi menor na mistura.

Em condições de terras altas, observou-se menor número de genótipos com severidade mais elevada de brusone nas folhas quando comparada à condição de várzea (Figura 1B; Tabela 2). Além de outros fatores esse fato pode ser atribuído às raças serem diferentes daquelas presentes mas várzeas. Nos genótipos isolados, os primeiros sintomas foram observados aos 37 DAP no plantio, e na composição das sementes misturadas (mistura varietal) os primeiros sintomas foram detectados aos $44 \mathrm{DAP}$, podendo ser observado que os níveis da doença mantiveram-se baixos durante todo o ciclo da cultura (Figura 1B). Esse atraso no aparecimento da doença nas parcelas da mistura varietal ocorreu, provavelmente, devido ao efeito barreira e diluição, típicos de misturas varietais. Esse fato é bastante favorável, uma vez que ao ocorrer à infecção mais tardiamente, a planta já se encontra menos suscetível. Prabhu \& Filippi (14) relatam que a fase mais crítica da planta ocorre aos 20 a 40 dias de idade, a qual a partir deste período ela torna-se mais resistente naturalmente.

Foi detectada uma elevada incidência da brusone nas panículas, tanto em condições de várzeas quanto em terras altas (Tabela 2), levando a uma acentuada redução na produtividade, já que nas panículas, os danos são diretos em virtude de seu efeito em diferentes componentes de produção (12). O desenvolvimento da doença nas panículas interfere, diretamente, no transporte de fotoassimilados para o enchimento dos grãos, comprometendo, desta forma, a produtividade. De modo geral, os genótipos com maior severidade da brusone nas panículas apresentaram menores níveis de produtividade. Entretanto, em alguns genótipos com elevada severidade nas panículas não resultou em menor produtividade. Este fato pode ser em virtude de um nível significativo de tolerância destes materiais à esta doença.

A composição em mistura varietal, na área de várzeas, proporcionou uma redução de $43 \%$ na incidência de brusone das panículas quando comparada à média geral das linhas isoladas. Como exemplo, o genótipo Ir 36 apresentou incidência da brusone nas panículas seis vezes superior quando cultivado em linhas isoladas, quando comparado ao cultivo em mistura varietal. Esse efeito na redução do nível da doença resultou em um aumento de mais de $100 \%$ no nível de produtividade (Tabela 2).

Os efeitos benéficos da mistura varietal têm sido mencionados e discutidos por outros autores (5, 6 e 20). Segundo estes, a redução do nível de doença ocorre através dos efeitos já mencionados da diluição e barreira. $\mathrm{O}$ efeito de diluição ocorre devido a uma maior distância entre as plantas suscetíveis, o que reduz a velocidade de disseminação da doença de planta a planta. O efeito barreira ocorre pela presença de plantas resistentes, funcionando como uma barreira física, impedindo a dispersão dos esporos do patógeno. Esse efeito é proporcional ao número de plantas resistentes, presentes na composição da mistura varietal (6). Zhu et al. (21), utilizando um genótipo suscetível e um resistente à brusone da panícula, obtiveram resultados satisfatórios no controle da doença, com uma redução de mais de $90 \%$ na incidência da doença no genótipo suscetível e de 30-40\% no genótipo resistente.

Não foi verificada no presente estudo relação entre a suscetibilidade à brusone nas folhas e nas panículas. Desse modo, genótipos que apresentaram alta suscetibilidade à brusone nas folhas, apresentaram baixa incidência da doença nas panículas, e vice versa. Estes resultados sugerem a existência de controle genético independente para a resistência à brusone nas folhas e nas panículas. Segundo Zhuang et al. (22), genes diferentes conferem resistência à brusone nas folhas e nas panículas em genótipos de arroz.

Em condição de terras altas, foi verificada baixa severidade da brusone nas folhas, porém, a doença nas panículas ocorreu em alta incidência, sendo a incidência média da mistura varietal maior que a encontrada nas condições de várzeas (Tabela 2). Segundo Bonman

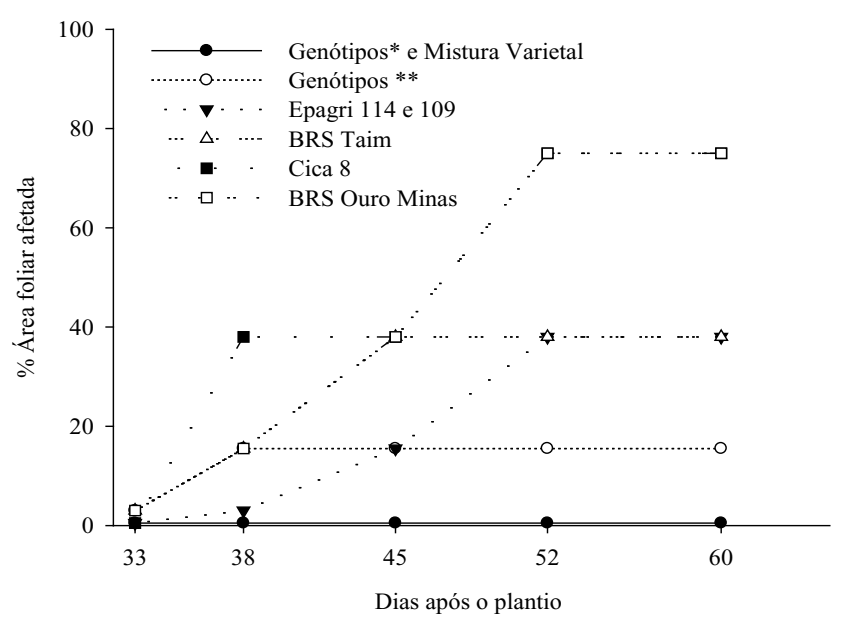

$\mathbf{A}$

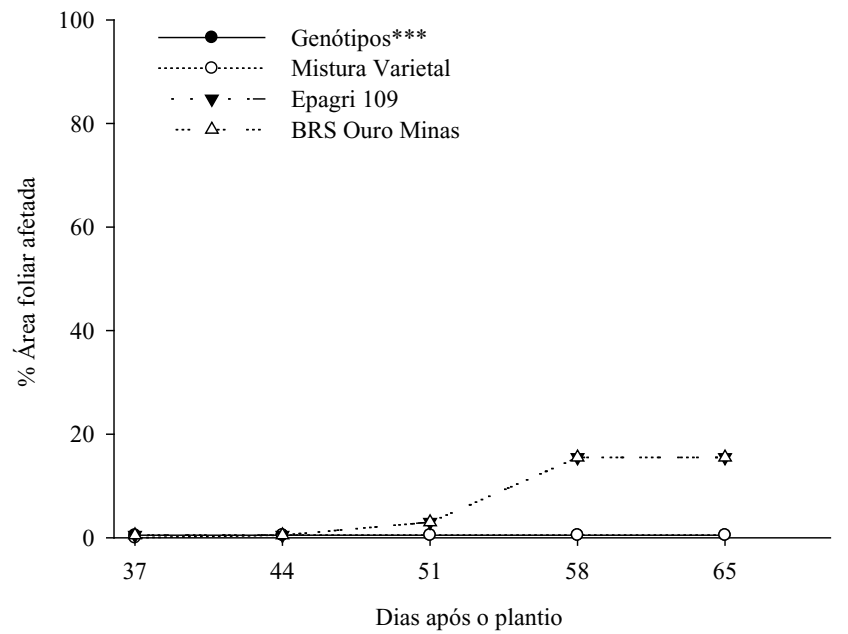

B

Figura 1. Progresso da severidade de brusone (Área Foliar Afetada) dos genótipos de arroz plantados isolados e em mistura em condições de várzea (A) e terras altas (B). Genótipos*= Diamante, CNA 8502, Javaé, Metica 1, BRS Formoso, BRS Alvorada, BRS Guará, BRS Jaçanã, BRS Fronteira, BRS Jaburu, BRS Biguá, BRS Pelotas, CNAI 9930, BR Irga 409, BG 90-2,Irga 417, IR 36, Irri 344, Orizica 1, Orizica Lhanos 4, Orizica Lhanos 5, Colômbia, Basmati, Eloni, IR 34, Cica 9, CNAI 9022, CNAI 5287, Mistura Varietal; Genótipos **= Best, Cica 7, Tetep; Genótipos*** = Genótipos*; Genótipos**; Epagri 114; BR Taim, Cica 8 . 
Tabela 2. Severidade da brusone nas folhas ${ }^{1}$, incidência ${ }^{2}$ nas panículas e produtividade média de genótipos plantados em linhas isoladas e em mistura varietal em condições de várzea e terras altas.

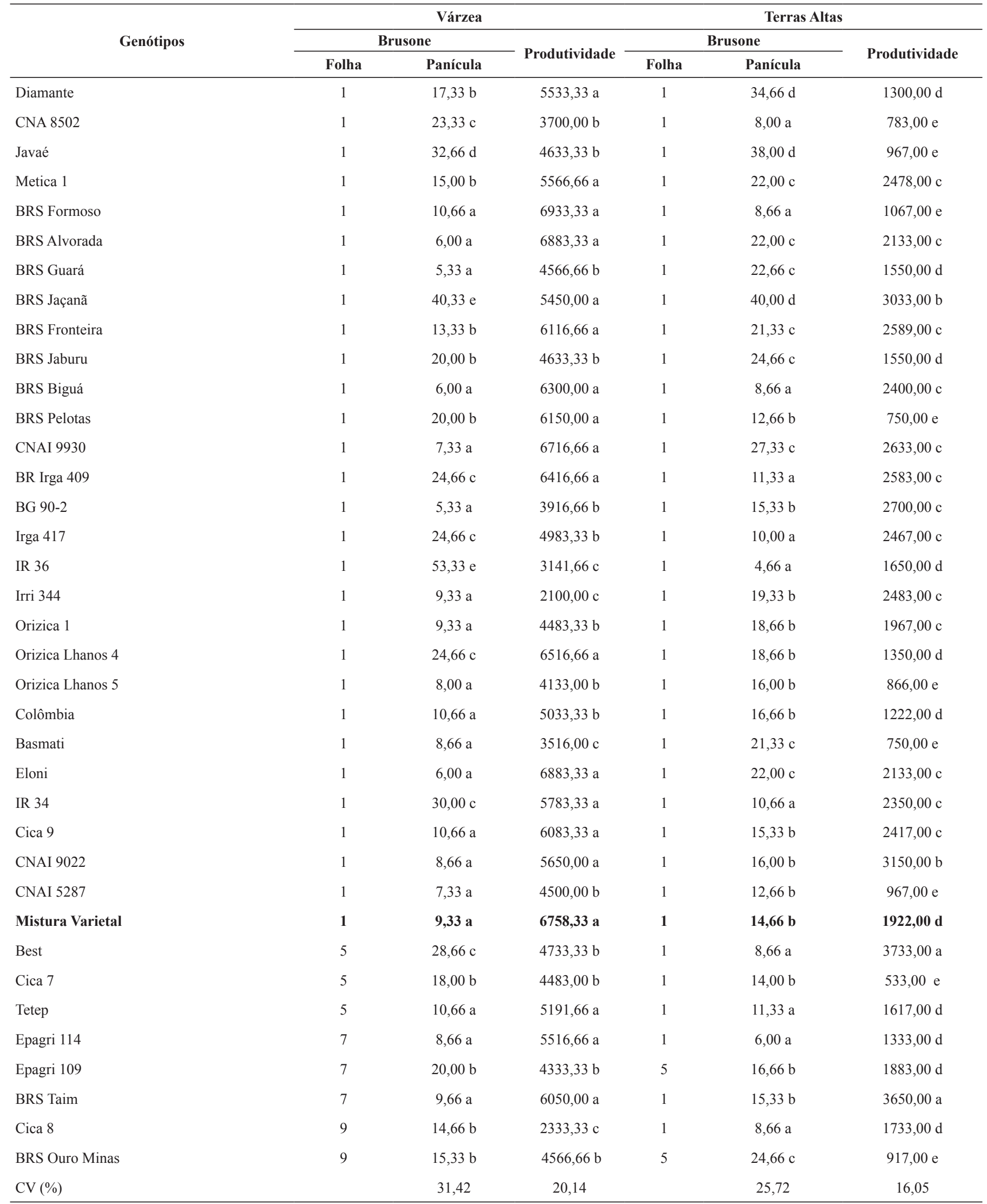

${ }^{1}$ Escala de notas de 0 a 9 proposta por Leung et al. (8). ${ }^{2}$ Médias seguidas pela mesma letra, não se difere estatisticamente pelo teste de Scott-Knott, ao nível de $5 \%$ de probabilidade. 
et al. (4), a brusone das panículas pode ocorrer sem ser precedida por um ataque severo de brusone das folhas. No entanto, mesmo em condições de terras altas e baixo inóculo a mistura ainda proporcionou uma redução de 13,25\% na incidência da doença. A maior incidência de brusone nas panículas, em relação às brusone nas folhas, observada nas duas condições estudadas, pode ter sido favorecida pela redução dos efeitos barreira e diluição. Como as panículas se encontram acima do dossel das plantas, a disseminação do inóculo pelo vento é mais fácil devido à redução do efeito de barreira física.

O estresse hídrico é outro fator que pode aumentar a suscetibilidade de genótipos de arroz à brusone nas panículas, devido ao acúmulo de nutrientes nas ramificações das mesmas (12). Os tecidos com elevado conteúdo de nutrientes, principalmente açúcares, são mais predispostos à infecção por M. oryzae (12). A maioria dos genótipos utilizados neste trabalho foram desenvolvidos para o cultivo em condição de várzea, assim, o cultivo em terras altas, mesmo com irrigação suplementar por aspersão, provavelmente não atendeu de forma plena as exigências hídricas requeridas, favorecendo a infecção pelo patógeno.

As raças de $M$. oryzae identificadas na área de várzeas foram IA-2, IB-2, IB-9, IB-19, IB-33, IC-8, IC-16 e IG-2, e em terras altas apenas a raça IB-6. A maioria dessas raças é diferente daquelas encontradas na amostragem populacional realizada por Anjos et al. (2) e Dias Neto et al. (8), na região de cultivo em várzea. Das raças identificadas nas parcelas das linhas isoladas somente os patótipos IB-33 e IB-9 foram encontrados por estes autores.

A produtividade dos genótipos de arroz em condição de várzea, nas linhas isoladas, variou de $2.100 \mathrm{~kg} \cdot \mathrm{ha}^{-1}$ a $6.933,33 \mathrm{~kg} \cdot \mathrm{ha}^{-1}$ (Tabela 2). A produtividade da mistura varietal foi de $6.758,33 \mathrm{~kg} \cdot \mathrm{ha}^{-1}$, sendo superior à produtividade de metade dos genótipos avaliados. Vale destacar que também com relação à produtividade média geral dos genótipos $\left(5.098,1 \mathrm{~kg} \cdot \mathrm{ha}^{-1}\right)$, houve um acréscimo na mistura de 1660, $2 \mathrm{~kg} \cdot \mathrm{ha}^{-1}$, um aumento de $25 \%$. Nakajima et al. (11), com mistura de multilinhas do genótipo Sasanishiki obtiveram um aumento de produtividade de $10,3 \%$ em relação à média dos componentes.

Em condições de terras altas a produtividade variou de $533 \mathrm{~kg} \cdot \mathrm{ha}^{-1}$ (Cica 7) a $3.733 \mathrm{~kg} \cdot \mathrm{ha}^{-1}$ (Best), nas linhas isoladas (Tabela 2). A produtividade média das linhas isoladas foi de $1.888 \mathrm{~kg} \cdot \mathrm{ha}^{-1}$. Nestas condições, a mistura varietal proporcionou resultados de produtividade superior ao da média geral, $1.922 \mathrm{~kg} \cdot \mathrm{h}^{-1}$, o que corresponde a um aumento de $1,76 \%$. Deve-se levar em consideração que a produtividade pode ter sido prejudicada em função dos genótipos não serem adaptados e portanto, não recomendados às condições de terras altas. A maior parte dos genótipos que apresentaram elevada severidade da brusone nas panículas apresentou, também, baixa produtividade, como é o caso dos genótipos: Javaé, Basmati, Ouro Minas e outros. Porém, outros genótipos como o Jaçanã, apesar da elevada severidade da brusone nas panículas, apresentaram elevada produtividade, tanto nas condições de várzeas como em terras altas. Esse fato pode ser devido ao alto nível de tolerância à brusone nas panículas nestes materiais. A produtividade média obtida pelos genótipos em condição de terras altas foi significativamente inferior à produtividade média obtida na condição de várzea, demonstrando a sensibilidade das cultivares de arroz ao estresse hídrico.

Do ponto de vista prático e financeiro fica difícil o manejo cultural e o controle de raças de brusone utilizando-se um grande número de genótipos como o que foi utilizado no presente estudo, sendo portanto, uma mistura com menor número de genótipos mais adequado. Neste caso, para locais onde se conhece a proporção e as raças presentes também se faz necessário estudos visando a rotação de genes, desde que o monitoramento das raças seja realizado com certa frequência. No presente trabalho foi possível verificar que a maioria dos genótipos testados apresentaram resistência à brusone nas condições avaliadas.

Acerca da possibilidade de utilização da mistura de cultivares como estratégia de controle da brusone do arroz é necessário que trabalhos adicionais sejam realizados, com o objetivo de avaliar as características agronômicas dos diferentes cultivares de arroz disponíveis atualmente no mercado para as diferentes regiões produtoras; visando a identificação de genótipos com características desejáveis similares para compor misturas varietais, bem como monitorar a flutuação populacional do patógeno, tendo em vista a possibilidade do surgimento de novas raças.

\section{REFERÊNCIAS}

1. Atkins, J.G.; Robert, A.L.; Adair, C.R.; Goto, K.; Kozaka, T.; Yanagita, R.; Yamada, M.; Matsumoto, S. An international set of rice varieties for differentiating races of Pyricularia oryzae. Phytopathology, Ithaca, v. 57, p.297-301, 1967.

2. Anjos, L.M.; Santos, G.R.; Dias Neto, J.J. Identificação de raças fisiológicas de Magnaporthe grisea em áreas de arroz irrigado no Estado do Tocantins. Tropical Plant Pathology, Brasilia, v.34, n.3, p.182-185, 2009.

3. Barr, M.E. Magnaporthe, Telimenella, and Hyponectria (Physosporellaceae). Mycologia, Philadelphia, v.69, p.952-966, 1977.

4. Bonman, J.M.; Khush, G.S.; Nelson, R.J. Breeding rice for resistance to pests. Annual Review Phytopathology, Danvers, v.20, p.507-528, 1992.

5. Browning, J.A.; Frey, K.J. Multiline cultivars as a means of disease control. Annual Review Phytopathology, Danvers, v.14, p.355-382, 1969.

6. Castro, A. Cultivar Mixtures. The Plant Health Instructor, St. Paul, 2001. DOI: 10.1094/PHI-A 2001-1230-01.

7. Couch, B.C.; Kohn, L.M. A multilocus gene genealogy concordant with host preference indicates segregation of a new species Magnaporthe oryzae, from M. grisea. Mycologia, Philadelphia, v.94, p.683-693, 2002.

8. Dias Neto, J.J.; Santos, G.R.; Anjos, L.M.; Rangel, P.H.N.; Ferreira, M.E. Hot spots for diversity of Magnaporthe oryzae physiological races in irrigated rice fields in Brazil. Pesquisa Agropecuária Brasileira, Brasília, v.45, n.3, p.252-260, 2010.

9. Leung, H.; Borromeo, E.S.; Bernardo, M.A.; Notteghem, J.L. Genetic analysis of virulence in the rice blast fungus Magnaporthe grisea. Phytopathology, Ithaca, v.78, n.9, p.1227-1233, 1988.

10. Nakajima, T.; Sonoda, R.; Yaegashi, H. Effect of a multiline of rice cultivar Sasanishiki and its isogenic lines on suppressing rice blast disease. Annals of the Phytopathological Society of Japan, Tokyo, v.62, p.227-233, 1996.

11. Nakajima, T.; Sonoda, R.; Yaegashi, H.; Saito, H. Factors Related to suppression of leaf blast disease with a multiline of rice cultivar Sasanishiki and its isogenic lines. Annals of the Phytopathological Society of Japan, Tokyo, v.62, p.360-364, 1996.

12. Prabhu, A.S.; Araújo, L.G.; Faustina, C.; Berni, R.F. Estimativa de danos causados pela brusone na produtividade de arroz de terras altas. Pesquisa Agropecuária Brasileira, Brasília, v.38, n.9, p.1045-1051, 2003.

13. Prabhu, A.S.; Filippi, M.C. Graus de resistência à brusone e produtividade de cultivares melhoradas de arroz de terras altas. Pesquisa Agropecuária Brasileira, Brasília, v.36, n.12, p.1453-1459, 2001.

14. Prabhu, A. S.; Filippi, M.C. Brusone em arroz: controle genético, progresso e perspectivas. Santo Antônio de Goiás: Embrapa Arroz e Feijão, 2006. 387p.

15. Rodríguez, R.E.S.; Rangel, P.H.N.; Morais, O.P. Estimativas de parâmetros genéticos e de respostas à seleção na população de arroz irrigado CNA 1. Pesquisa Agropecuária Brasileira, Brasília, v.33, n.5, p.685-691, 1998.

16. Santos, G.R.; Rangel, P.H.N.; Santiago, C.M.; Leão, F.F.; Marra, B.; Almeida Junior, D. Reação a doenças e caracteres agronômicos de genótipos de arroz de várzeas no estado do Tocantins. Revista Agropecuária Técnica, Areia, v.26, n.1, 2005.

17. Santos, G.R; Saboya, L.M.F; Rangel, P.N.N; Oliveira Filho, J.C. Resistência de genótipos de arroz a doenças no sul do Estado do Tocantins. Bioscience Journal, Uberlândia, v.18, n.1, p.3-12, 2002. 
18 Sester, M.; Raboin, L.M.; Ramanantsoanirina, A.; Tharreau, D. Toward an integrated strategy to limit blast disease in upland rice. In: ENDURE Inf ternational Conference, 2008, La Grande-Motte. Anais. La Grande-Motte: Anglais, 2008. p. 12-15.

19 Scheuermann, K.K.; Eberhardt, D.S. Avaliação de fungicidas para o controle da brusone de panícula na cultura do arroz irrigado. Revista de Ciências Agroveterinárias, Lages, v.10, n.1, p.23-28, 2011.

20. Zhu, Y.; Chen, H.; Fan, J.; Wang, Y.; Chen, J.; Fan, J.X.; Yang, S.; Hu, L.; Leung, H.; Mew, T.W.; Teng, P.S.; Wang, Z.; Mundt, C.C. Genetic diver- sity and disease control in rice. Nature, London, v.406, p.718-722, 2000.

21. Zhu, Y.Y.; Fang, H.; Wang, Y.Y.; Fan, J.X.; Yang, S.S.; Mew, T.W.; Mundt, C.C. Panicle blast and canopy moisture in rice cultivar mixtures. Phytopathology, Ithaca, v.95, n.04, p.433-438, 2005.

22. Zhuang, J.Y.; Ma, W.B.; Wu, J.L.; Chai, R.; Lu, J.; Fan, Y.; Jin, M.; Leung, H.; Zheng, K. Mapping of leaf and neck blast resistance genes with resistance gene analog, RAPD and RFLP in rice. Euphytica, Wageningen, v.128, p.363-370, 2002. 